\title{
Diagnosing the Growth of Equatorial Typhoon Vamei (2001) from an Energy Standpoint
}

\author{
Gin-Rong Liu ${ }^{1,2, *}$, Chung-Chih Liu ${ }^{3}$, Ching-Shun Huang ${ }^{2}$, Tang-Huang Lin ${ }^{1,4}$, \\ Wann-Jin Chen ${ }^{5}$, and Chun-Chieh Chao ${ }^{2}$ \\ ${ }^{1}$ Center for Space and Remote Sensing Research, National Central University, Jhongli, Taiwan \\ ${ }^{2}$ Institute of Atmospheric Physics, National Central University, Jhongli, Taiwan \\ ${ }^{3}$ Teaching Center of Natural Science, Minghsin University of Science and Technology, Hsinchu, Taiwan \\ ${ }^{4}$ Institute of Space Science, National Central University, Jhongli, Taiwan \\ ${ }^{5}$ Department of Electronic Engineering, Ta Hwa Institute of Technology, Hsinchu, Taiwan
}

Received 8 September 2009, accepted 3 December 2009

\begin{abstract}
Surprisingly, on 27 December 2001, a storm named Typhoon Vamei formed near in Singaporean waters. An examination on the SSM/I-derived rainfall rates and air-sea parameters showed that significant higher latent heat release and air-sea energy flux during convective rainfall activities played a key role in the typhoon's growth. A quantitative analysis revealed that the energy flux from the ocean to the atmosphere and the latent heat release during the rainfall activities both increased significantly during the initial growth stage. However, the values rapidly decreased just before the storm reached typhoon strength. Separately, in contrast to a case that occurred in 1999, the total thermal energy calculated from Typhoon Vamei's formation was two times higher. Thus, despite a very weak Coriolis force in the equatorial belt, the special terrain of Borneo Island and narrow channel in the equatorial South China Sea caused a Borneo vortex via northeasterly cold surges, together with the accumulated energy was sufficiently strong enough to induce the formation of Typhoon Vamei.
\end{abstract}

Key words: Equatorial typhoon, Typhoon formation, Energy flux

Citation: Liu, G. R., C. C. Liu, C. S. Huang, T. H. Lin, W. J. Chen, and C. C. Chao, 2010: Diagnosing the growth of equatorial Typhoon Vamei (2001) from an energy standpoint. Terr. Atmos. Ocean. Sci., 21, 817-827, doi: 10.3319/TAO.2009.12.03.01(A)

\section{INTRODUCTION}

As early as 1968, Gray (1968) indicated there were six dynamic thermal conditions associated with the formation of tropical cyclones, where the Coriolis force was one of them. It is thus logical to assume that the region $300 \mathrm{~km}$ north and south of the Earth's equator should be tropical cyclone-free. Yet, tropical cyclones are indeed observed within 5 degrees of the equator albeit rarely (Gray 1968; Anthes 1982; McBride 1995; Chang et al. 2003). However, during the winter monsoon in the northern hemisphere, northeasterly cold surges occasionally drift south toward the equator from the East Asian continent (Chang et al. 1983; Chang and Chen 1992). The southeastern portion of the main surge wind belt in the South China Sea is located near Borneo Island. A quasi-stationary low level cyclonic circu-

\footnotetext{
* Corresponding author

E-mail:grliu@csrsr.ncu.edu.tw
}

lation near the island's northwest coast is considered a notable feature of the winter climatology (Johnson and Houze 1987). This circulation is called the Borneo vortex, which is often associated with deep convection, intense latent heat release (LHR) and upper-level divergence. However, as a significant portion of the vortex circulation is usually situated above the land surface, it is very difficult for the vortex to develop into a tropical cyclone. Chang et al. (2003) used three sets of wind data to study the low-level wind fields and determine the roles played by the monsoon cold surges, pre-existing disturbances, and upper level divergence before Typhoon Vamei's formation. The datasets included a 1 by 1 degree wind analysis at $850 \mathrm{hPa}$ (Hogan and Brody 1993) from the Naval Operational Global Atmospheric Prediction System, a 25 by $25 \mathrm{~km}$ surface wind analysis from QuikSCAT data, and a 2.5 by 2.5 degree wind reanalysis at the surface and $925 \mathrm{hPa}$ (Kalnay et al. 1996) via the National 
Centers for Environmental Prediction/National Center for Atmospheric Research. Their results showed that the special terrain with the narrow channel of the equatorial South China Sea enhances the surging northeast wind and the shear vorticity. The combined effects from a one-week long cold surge in the South China Sea, a four-day long off-shore forwarding Borneo vortex and cross-equatorial surge winds helped spur the formation of Typhoon Vamei. Based upon theoretical and statistical analysis, they also suggested that the probability of such a typhoon to develop was roughly once every 100 - 400 years. Chang et al. (2005) investigated the impact on deep convection with respect to the formation of equatorial tropical cyclone due to interactions among three different motion systems including the Borneo vortex, the northeast cold surge and the intraseasonal Madden Julian Oscillation (MJO). They suggested that the MJOrelated circulation opposes the cold surge and vortex circulations. Chambers and Li (2007) used a mesoscale model to examine the mechanisms of formation and intensification of Typhoon Vamei. Their vorticity analysis shows that the increases in vorticity at low level and potential vorticity at upper are crucial for the build up of a cyclonic layer throughout the troposphere.

However, aside from these factors, additional variables should also have contributed to Typhoon Vamei's formation. The effect of the ocean on tropical cyclone genesis and development has been well known for decades. The basic theory (Emanuel 1986) and numerical experiments (Emanuel 1995) showed that the intensity of tropical cyclones depends strongly on air-sea interaction. A decrease in the sea surface temperature gradient between the eye of a tropical cyclone and the surrounding water is considered to be able to increase the maximum wind speed (Schade 2000; Emanuel 2007). There is evidence that sea surface temperatures and power dissipated by cyclones over the last few decades are indeed correlated (Emanuel 2005; Elsner et al. 2006) and the intensity of a typhoon passing over a warm and deep mixed water increase rapidly (Shay et al. 2000; Goni and Trinanes 2003). Moreover, Hendricks et al. (2004) propose the concept of vortical hot towers which are strong cumulus updraughts. The vortical hot towers generate strong vorticity anomalies of both positive and negative sign and play an important role in the genesis of tropical cyclones. Some observational evidence for the existence and interactions of vortical hot towers in developing cyclones was provided by Reasor et al. (2005) and Sippel et al. (2006). Montgomery et al. (2006) and Tory et al. (2007) continued investigation of the vortical hot towers and found that the dominant forcing for intensification of tropical cyclones was LHR in convection associated with the ensemble vortical hot towers. Therefore, it is reasonable to also take into account the "energy effect" of a typhoon's formation and evolution. Juneng et al. (2007) analyzed the output of Penn State University - National Center for Atmospheric Research mesoscale model MM5 and suggested the important role of the latent heat flux in the genesis and intensification of Typhoon Vamei. In order to provide a more comprehensive analysis from an energy standpoint, this study attempts to delineate the relevant energy fluxes and variations associated with Typhoon Vamei.

\section{DATA}

The Special Sensor Microwave/Imager (SSM/I) is carried onboard the Defense Meteorological Satellite Program (DMSP) sun-synchronous satellites which orbit the Earth at a height of $833 \mathrm{~km}$ and are oriented at an inclination of $98.8^{\circ}$ (Hollinger et al. 1990). Generally, any area on the Earth can be observed by these SSM/I sensors in less than 72 hours, except for two circular areas within a radius of $280 \mathrm{~km}$ located at the North and South Poles. The SSM/I sensors provide four channels $(19,22,37$, and $85 \mathrm{GHz})$, each having two polarization components (vertical and horizontal), except for the vertical polarization component at $22 \mathrm{GHz}$. The SSM/I data used in this research were acquired during December of 1999 and 2001. Although the satellite microwave data can penetrate through clouds, the brightness temperature is still affected by heavy rainfall. To filter out the microwave data that are significantly affected by large raindrops, the SSM/I data are discarded if two relationships fit within following conditions (Goodberlet and Swift 1992).

$T_{b}(19 V)>165 K$

$\left[T_{b}(37 V)-T_{b}(37 H)\right]<37 K$

where $T_{b}(19 \mathrm{~V}), T_{b}(37 \mathrm{~V})$, and $T_{b}(37 \mathrm{H})$, are the brightness temperatures observed at different channels. Each channel (19.35 and $37.0 \mathrm{GHz}$ ) has two polarization components (vertical and horizontal components; $\mathrm{V}$ and $\mathrm{H}$ ). The excluded heavy rainfall areas are simulated via interpolation.

The microwave scatterometer SeaWinds was launched on the QuickBird satellite in June 1999 (referred as QSCAT). The primary mission of the SeaWinds scatterometers is to measure winds near the ocean surface. It is essentially radar that transmits microwave pulses down to the sea surface and measures the energy that is scattered back to the instrument. This "backscattered" power is related to the sea surface roughness. The sea surface roughness is highly correlated with the near sea surface wind speed and direction. Hence, wind speed and direction at a height of 10 meters over the sea surface are retrieved from the scatterometer's backscattered power measurements. The QSCAT data was used in this study to analyze the dynamic conditions near the sea surface.

The Geostationary Meteorological Satellite (GMS-5) is a geostationary meteorological satellite that observes from 
a height of $36000 \mathrm{~km}$ over the meridian at $140^{\circ} \mathrm{E}$. It provides hourly, plus 4 half-hourly observations in one visible, two infrared (IR1, 10.5 - $11.5 \mu \mathrm{m}$ and IR2, 11.5 - $12.5 \mu \mathrm{m}$ ), and one water vapor (WV, $6.5-7.0 \mu \mathrm{m})$ channels. The IR1 infrared channel was used to understand the development of cloud systems encompassing a region from $5^{\circ} \mathrm{N}-5^{\circ} \mathrm{S}$ to $102.5^{\circ}-112.5^{\circ}$ (referred hereafter as study area).

\section{METHODOLOGY}

Several satellite derived air-sea parameters are used in this research. Owing to the advantage of microwave cloud penetration, SSM/I microwave measurements were used in this study. The sea surface temperature and near sea surface air humidity were derived from statistical algorithms proposed by Liu et al. (2001). These statistical regression equations were established via satellite brightness temperatures and ship-measured data. Although the frequencies of SSM/I observations do not include $10.6 \mathrm{GHz}$ and may not be sensitive enough to detect the actual sea surface temperature in regions with high variability of water vapor, the present statistical algorithm may be still valid only for the oceans around South China Sea due to low variability of water vapor. Based upon the method proposed by Konda et al. (1996), the modified Bowen ratio method (Liu et al. 2002, 2003) was employed, where additional improvements were added to reduce the computational difficulty in deriving the near sea surface air temperature in this study. The retrieval model can be written as follows:

$T_{a}=T_{s}-\left[0.2 \times\left(q_{s}-q_{a}\right) \frac{q_{*}\left(T_{a}\right)}{q_{a}}\left(1 / \frac{\partial q_{*}}{\partial T}\right)_{T=T_{a}}\right]$

where $q_{*}$ is the saturated specific humidity at the near sea surface air temperature $\left(T_{a}\right)$, and $q_{s}$ is the saturated specific humidity at the sea surface temperature $\left(T_{s}\right)$. Since $T_{s}, q_{s}$, and the near sea surface air humidity $\left(q_{a}\right)$ can be estimated from satellite data, $T_{a}$ can be derived through the aforementioned retrieval equation by using an iterative technique. The near sea surface wind speed at a height of 10 meters is estimated by using the statistical regression equation proposed by Goodberlet et al. (1992). The bulk formula, the latent heat flux (LHF) and the sensible heat flux (SHF) between the atmosphere and the ocean can thereby be denoted as:

$S H F=\rho c_{p} c_{h}\left(T_{s}-T_{a}\right) u$

$L H F=l \rho c_{e}\left(q_{s}-q_{a}\right) u$

where $\rho$ is the air density, $l$ is the latent heat of evaporation, $c_{p}$ is the specific heat, $c_{h}$ and $c_{e}$ are the bulk coefficients and $u$ is the near sea surface wind speed.
Many algorithms have been proposed in estimating the rainfall of storms via satellite microwave data. A thirdgeneration operational SSM/I rainfall retrieval algorithm, developed by the National Oceanic and Atmospheric Administration/National Environmental Satellite, Data and Information System (NOAA/NESDIS) is used by NESDIS. This algorithm applied SSM/I radiance measurements to retrieve rainfall rate and was also employed in this study due to its versatile rainfall estimations from an $85 \mathrm{GHz}$ scattering standpoint over land, and a combination of the $85 \mathrm{GHz}$ scattering and 19/37 GHz emission approach over the ocean (Ferraro and Marks 1995; Ferraro et al. 1997). Following Rodgers and Pierce (1995), the LHR could be derived as follows:

$L H R=L \rho \int_{A} R d a$

where $\rho$ is the rainwater density, $L$ the condensation latent heat, $R$ the rain rate, $d a$ the incremental area, and $A$ the area of integration.

\section{RESULTS AND DISCUSSION}

A subsequent GMS-5 infrared image sequence (Figs. 1a - f) shows that some convective clouds emerged over the ocean near the northwest coast of Borneo. They continued to develop and eventually reached typhoon strength during the time period from 23 to 27 December 2001. The storm system was subsequently named Vamei. Meanwhile, a cold surge developed rapidly over the South China Sea and the location of the Borneo vortex center was near the northwest coast of Borneo at 1000 UTC 23 December 2001 (Fig. 2). From a sequence of QSCAT wind analysis (Figs. 3a - d), it shows that the vortex center moved in the southwest direction along the Borneo coast toward the equator. Afterwards, it remained over the ocean waters for several days. In addition, a strong northeasterly cold surge persisted, and was slightly deflected to the northwest of the vortex. This perhaps provided a source for background cyclonic vorticity (Chang et al. 2003) as the surge wind crossed the equator. These factors provided conducive for dynamic conditions necessary for the formation of the tropical cyclone.

Chang et al. (2003) used QSCAT derived wind fields covering the area from $7.5-12.5^{\circ} \mathrm{N}$ to $110.0-115.0^{\circ} \mathrm{E}$, which is an upstream region of the Borneo vortex in analyzing the time variations of the northern cold surge. A surge index was defined as the average of all northeasterly wind components from QSCAT reports within the aforementioned area. They suggested that the four-day lifecycle and strong intensity (surge index $>10 \mathrm{~m} \mathrm{~s}^{-1}$ ) was a key condition for the environmental vortex intensification, which ultimately triggered Typhoon Vamei to be born. The time series of the 

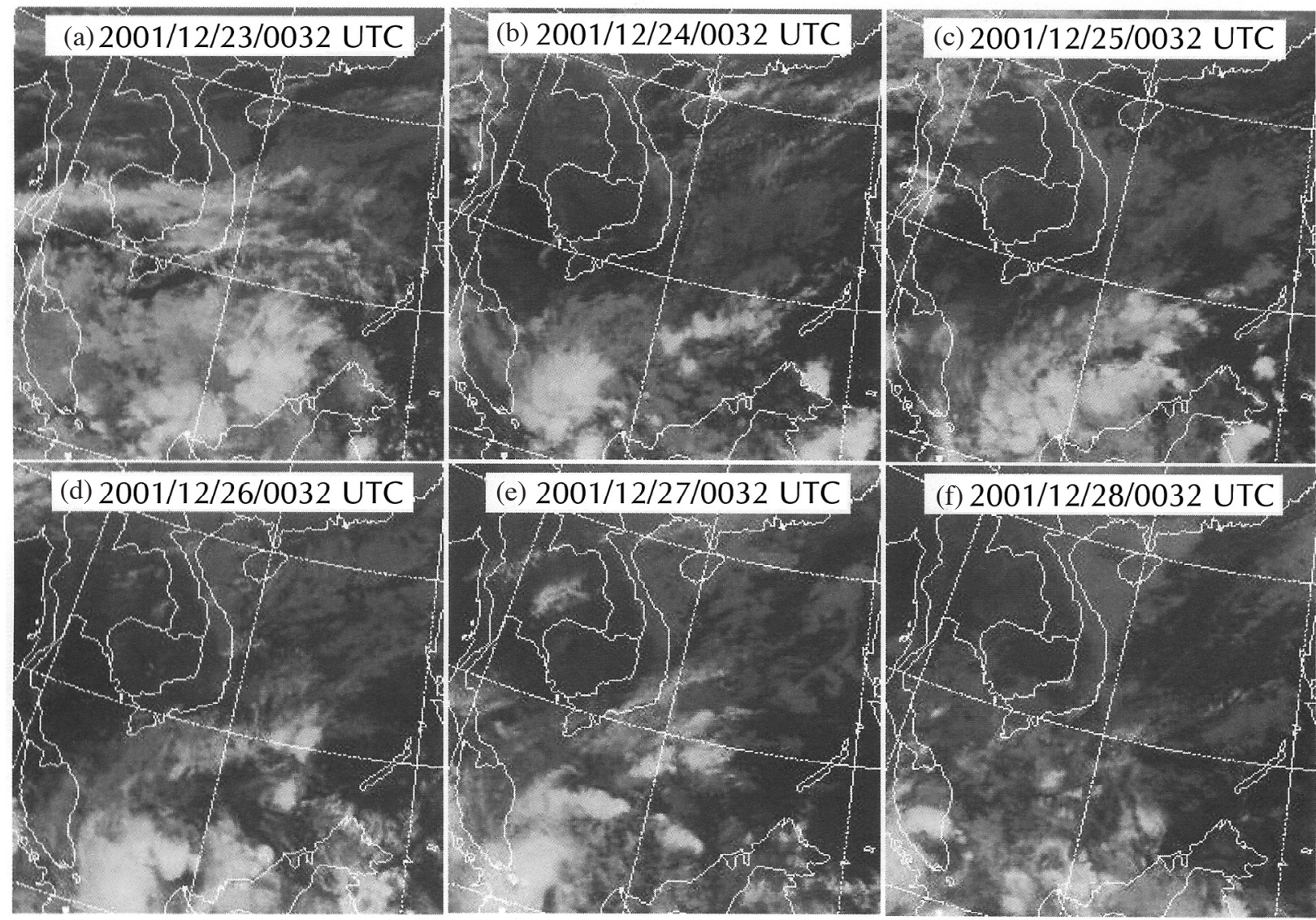

Fig. 1. A subsequent GMS-5 infrared image sequence during 23 - 27 December 2001.

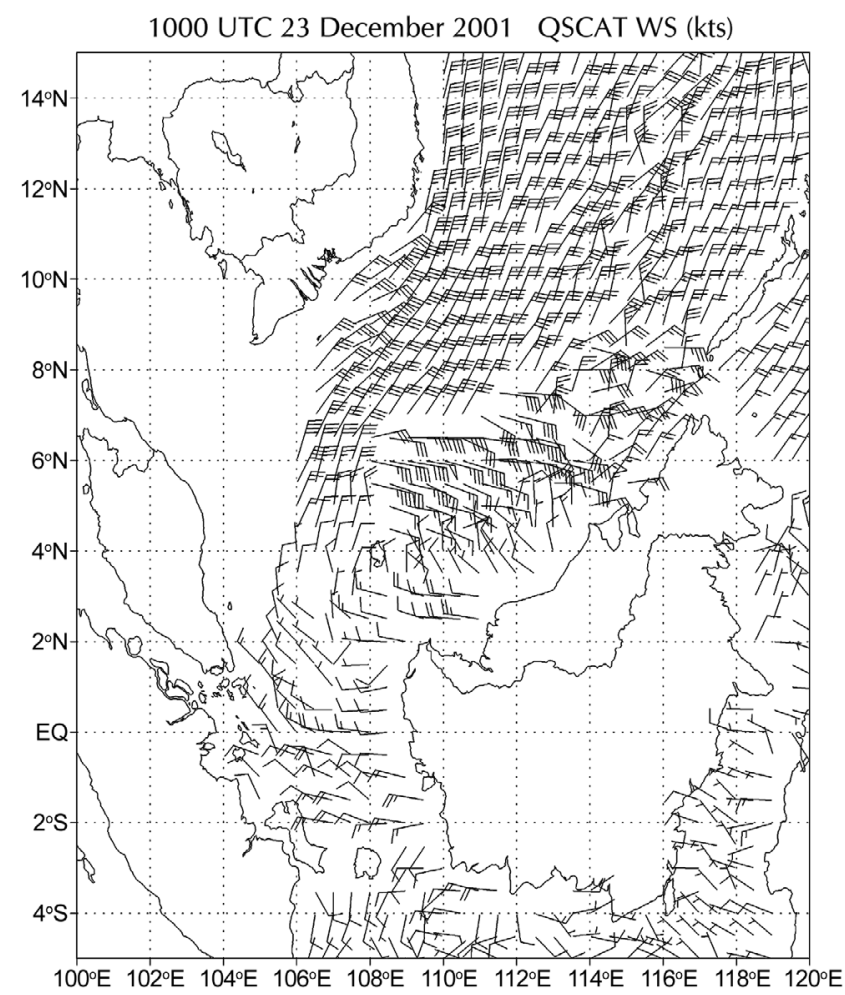

Fig. 2. The QSCAT surface wind at 1000 UTC 23 December 2001. cold surge index in December 1999 and 2001 are shown in Fig. 4. Following the suggestions made by Chang et al. (2003), four suitable typhoon formation time periods were investigated (Fig. 4): (1) 20 - 25 December 2001; (2) 27 - 30 December 2001; (3) 6 - 9 December 1999; and (4) 21 - 26 December 1999. Among the four time periods, a typhoon development was only seen in the first one. But why is this so? To shed light on this question with a different approach, an energy analysis was performed by this study.

Figure 5 shows the time serial analysis of the relative vorticity in the study area. Typhoon Vamei formed at 0600 UTC 27 December 2001 and the cloud clusters were observed over the ocean from 19 December 2001. The tropical cyclone's circulation slowly became more obvious and the relative vorticity increased sharply after 23 December 2001. Figure 6a shows that the sea surface temperature was higher during the time period from 17 to 25 December 2001. A similar trend could be observed in the near sea surface air temperature and wind speed variations during the same time period (Figs. $6 \mathrm{~b}$ and e). Meanwhile, the difference between the sea surface temperature and near sea surface air temperature increased sharply (Fig. 6c) and the near sea surface air humidity slowly decreased (Fig. 6d). Consequently, both the air-sea sensible heat flux and latent heat flux also 
(a)

2200 UTC 24 December 2001 QSCAT WS (kts)

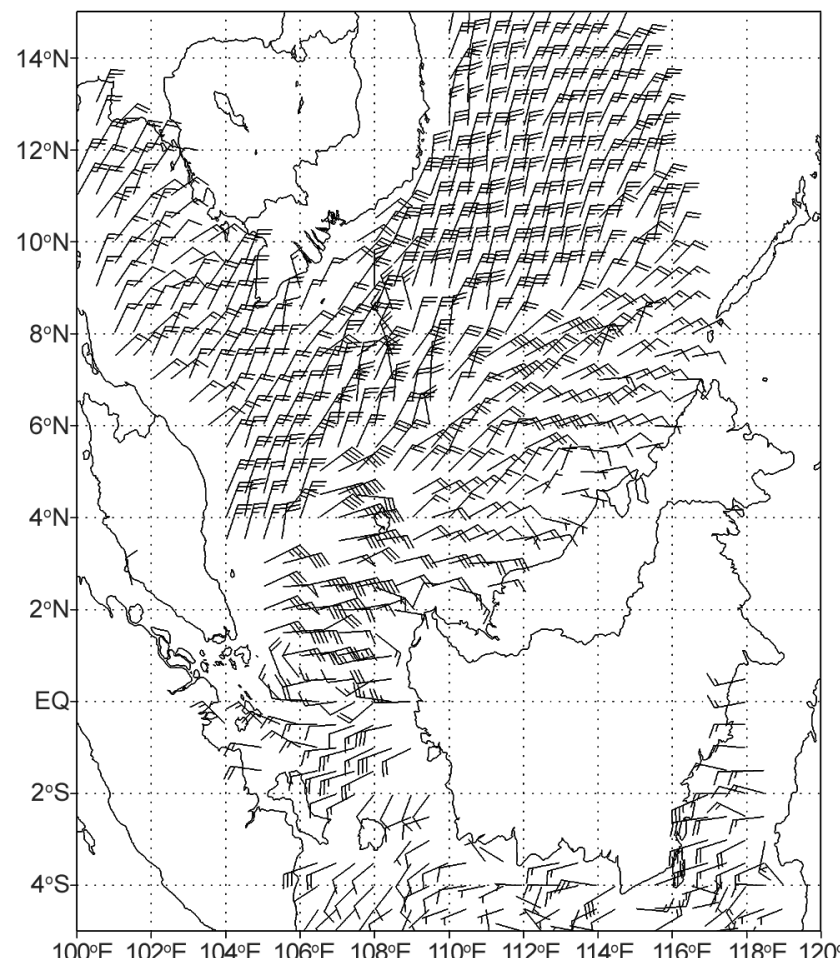

$100^{\circ} \mathrm{E} 102^{\circ} \mathrm{E} 104^{\circ} \mathrm{E} 106^{\circ} \mathrm{E} 108^{\circ} \mathrm{E} 110^{\circ} \mathrm{E} 112^{\circ} \mathrm{E} 114^{\circ} \mathrm{E} 116^{\circ} \mathrm{E} 118^{\circ} \mathrm{E} 120^{\circ} \mathrm{E}$ (b)

2200 UTC 25 December 2001 QSCAT WS (kts)

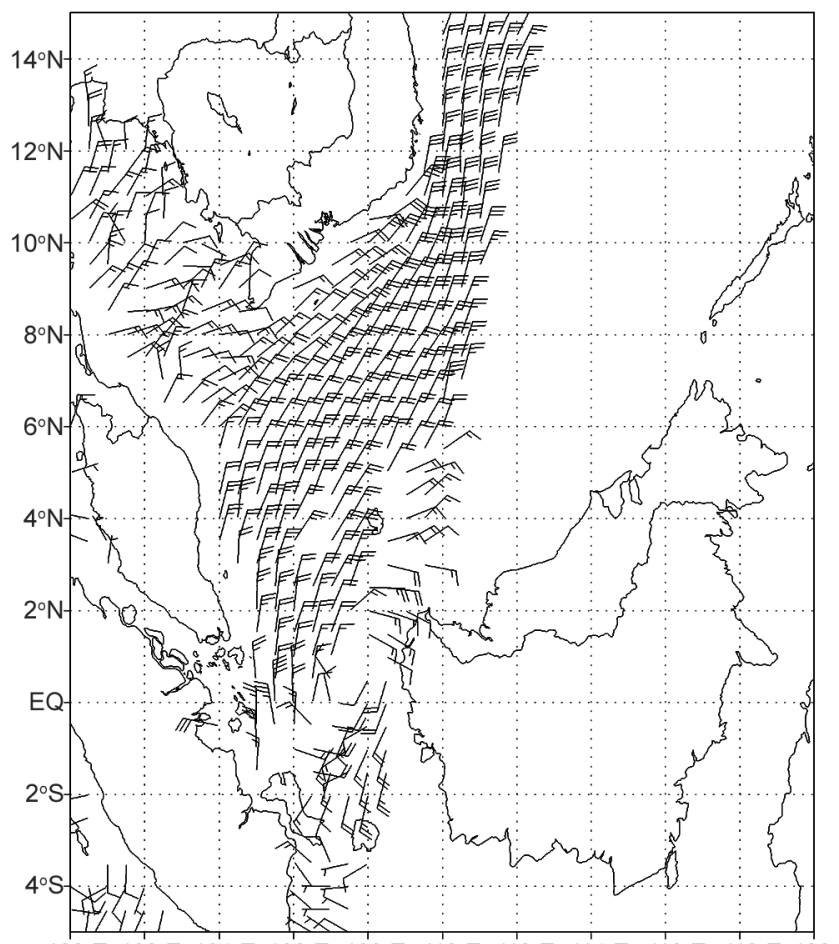

$100^{\circ} \mathrm{E} 102^{\circ} \mathrm{E} 104^{\circ} \mathrm{E} 106^{\circ} \mathrm{E} 108^{\circ} \mathrm{E} 110^{\circ} \mathrm{E} 112^{\circ} \mathrm{E} 114^{\circ} \mathrm{E} 116^{\circ} \mathrm{E} 118^{\circ} \mathrm{E} 120^{\circ} \mathrm{E}$ (c)

1000 UTC 26 December 2001 QSCAT WS (kts)

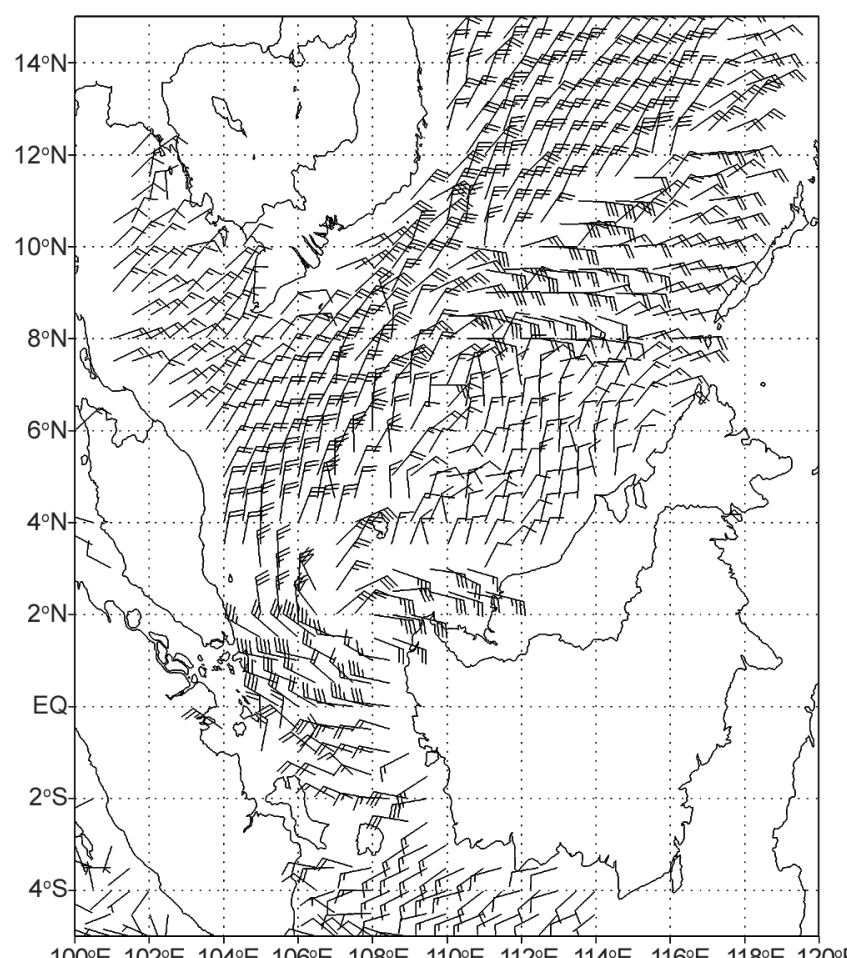

(d)

2200 UTC 27 December 2001 QSCAT WS (kts)

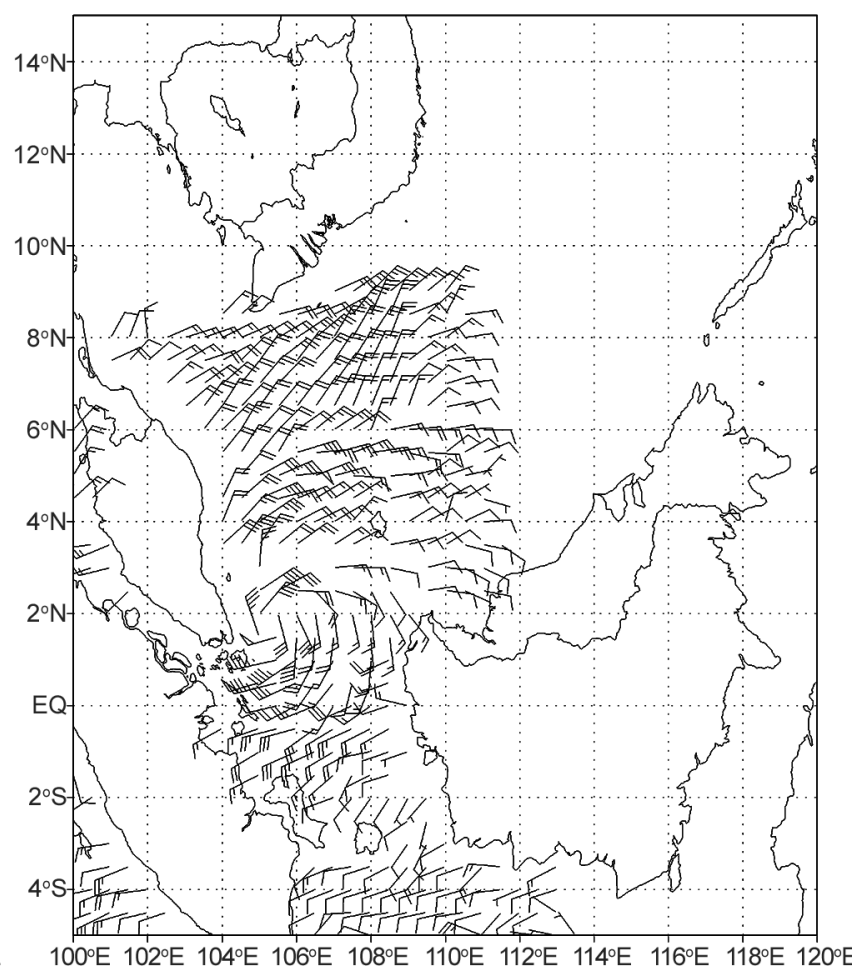

Fig. 3. A sequence of QSCAT wind analysis during 24 - 27 December 2001. 


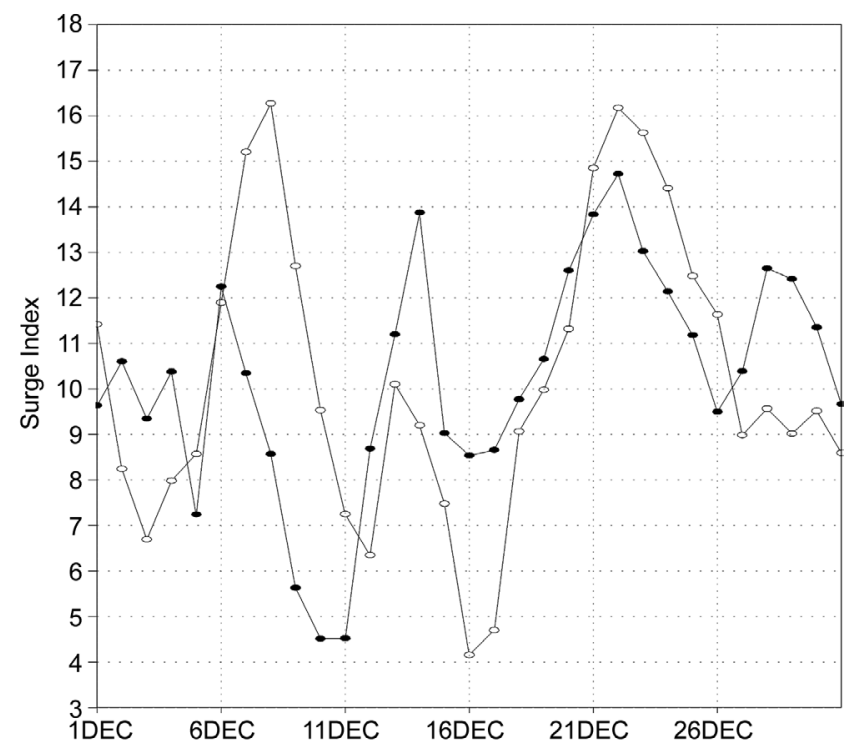

Fig. 4. The time series of cold surge index (Chang et al. 2003) (Unit: $\mathrm{m} \mathrm{s}^{-1}$ ) covering the area from $7.5^{\circ} \mathrm{S}$ to $12.5^{\circ} \mathrm{N}$ and 110 to $115^{\circ} \mathrm{E}$ in December 1999 and 2001 (hollow circles for 1999 and solid dots for 2001).

(a)

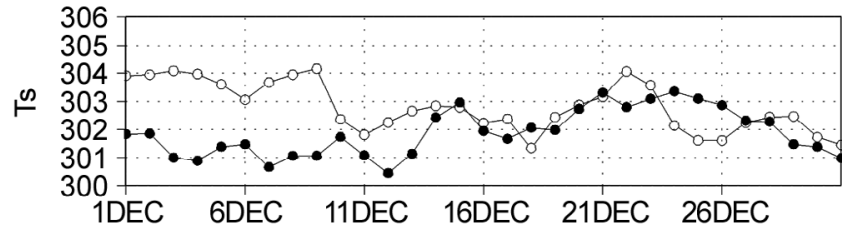

(b)

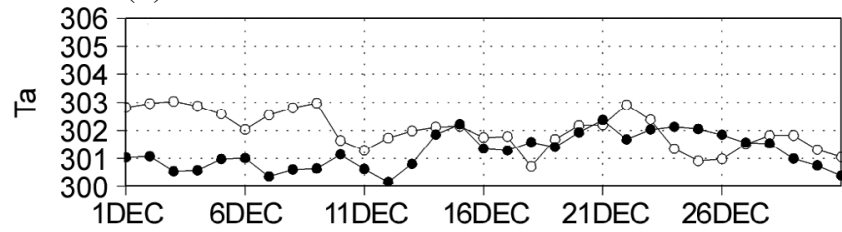

(c)

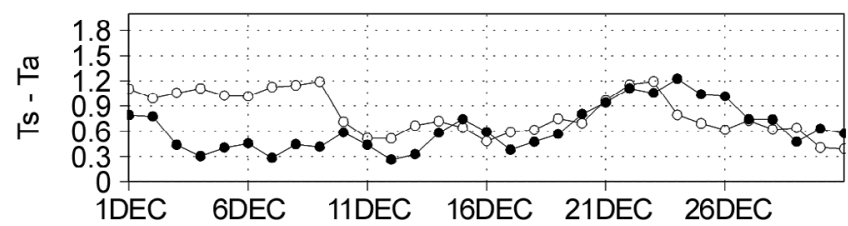

(d)

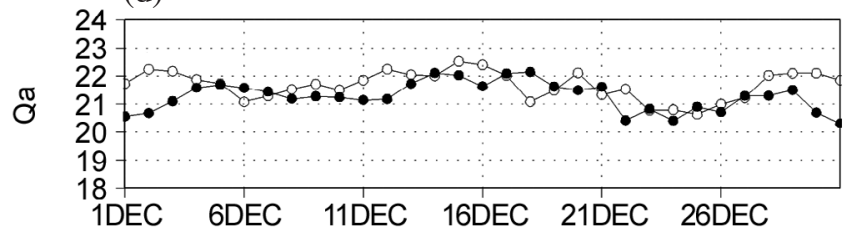

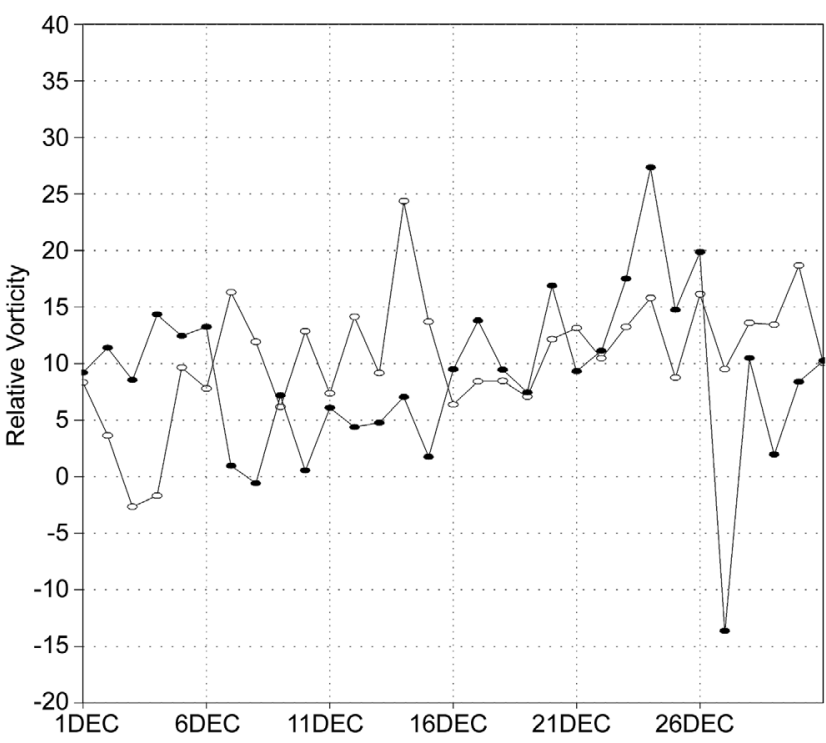

Fig. 5. The time serial mean relative vorticity analysis (Unit: $10^{-16} \mathrm{~s}^{-1}$ ) covering the area from $5^{\circ} \mathrm{S}$ to $5^{\circ} \mathrm{N}$ and 102.5 to $112.5^{\circ} \mathrm{E}$ (hollow circles for 1999 and solid dots for 2001).

(e)

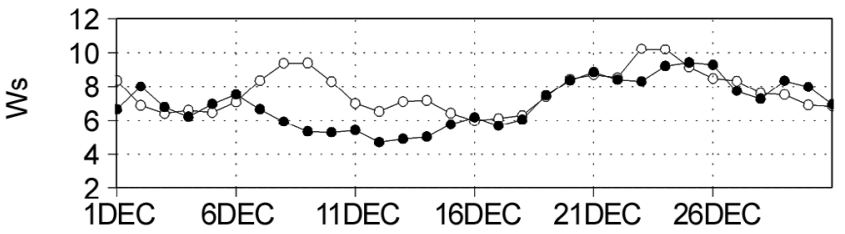

(f)

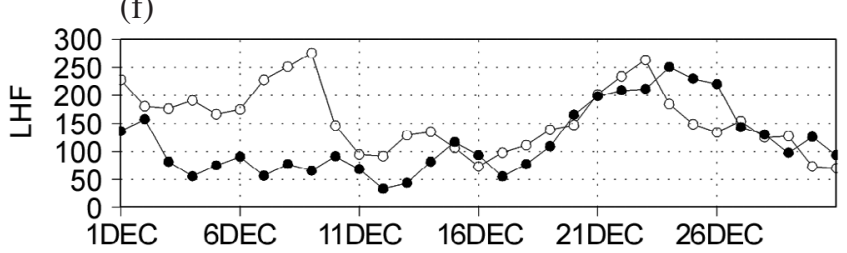

(g)

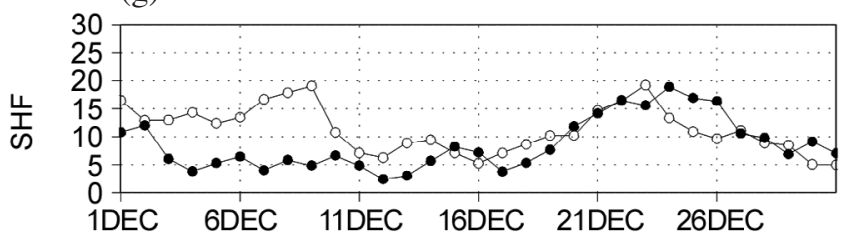

(h)

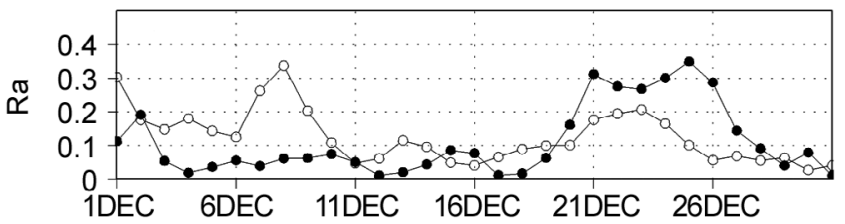

Fig. 6. The mean air-sea parameters covering the area from $5^{\circ} \mathrm{S}$ to $5^{\circ} \mathrm{N}$ and 102.5 to $112.5^{\circ} \mathrm{E}$ for December 1999 (hollow circles) and 2001 (solid dots). (a) sea surface temperature in K; (b) near sea surface air temperature in K; (c) difference between sea surface temperature and near sea surface air temperature in $\mathrm{K}$; (d) near sea surface air humidity in $\mathrm{g} \mathrm{kg}^{-1}$; (e) near sea surface wind speed in $\mathrm{m} \mathrm{s}^{-1}$; (f) air-sea latent heat flux in w $\mathrm{m}^{-2}$; (g) airsea sensible heat flux in $\mathrm{w} \mathrm{m}^{-2}$; (h) rain rates in $\mathrm{mm} \mathrm{hr}^{-1}$. 
rose notably (Figs. 6f and g), which could be attributed to the significant wind speed increases and larger temperature/ humidity differences between the air and sea during the typhoon pre-formation period. In addition, the variations in the rainfall rates (Fig. 6h) enjoyed a close correlation with the air-sea sensible and latent heat flux. The values of the air-sea sensible and latent heat flux as well as rainfall rates all reached their peak levels before the typhoon was born, but subsequently dropped significantly after 26 December, signaling its probably short lifecycle. This may explain why no typhoon warning was issued by the Japanese or local weather agencies. Moreover, the SSM/I derived mean distribution of the total air-sea heat flux (SHF + LHF) and rainfall rates on 25 December 2001 were also very similar (Figs. 7 and 8), revealing a strong energy source within the study area. This all indicated that the energy released from the rainfall process and air-sea interaction could provide the required energy for a typhoon's growth.

Despite a strong surge index (Fig. 4), there was a weak mean relative vorticity value (Fig. 5) and energy source (Figs. 6f - h) during the time period from 27 to 30 December 2001 (the second suitable period), which explained why there was no tropical cyclone formation. Separately, during

\section{1/12/25 Mean LHF and SHF $\left(w^{-2}\right)$}

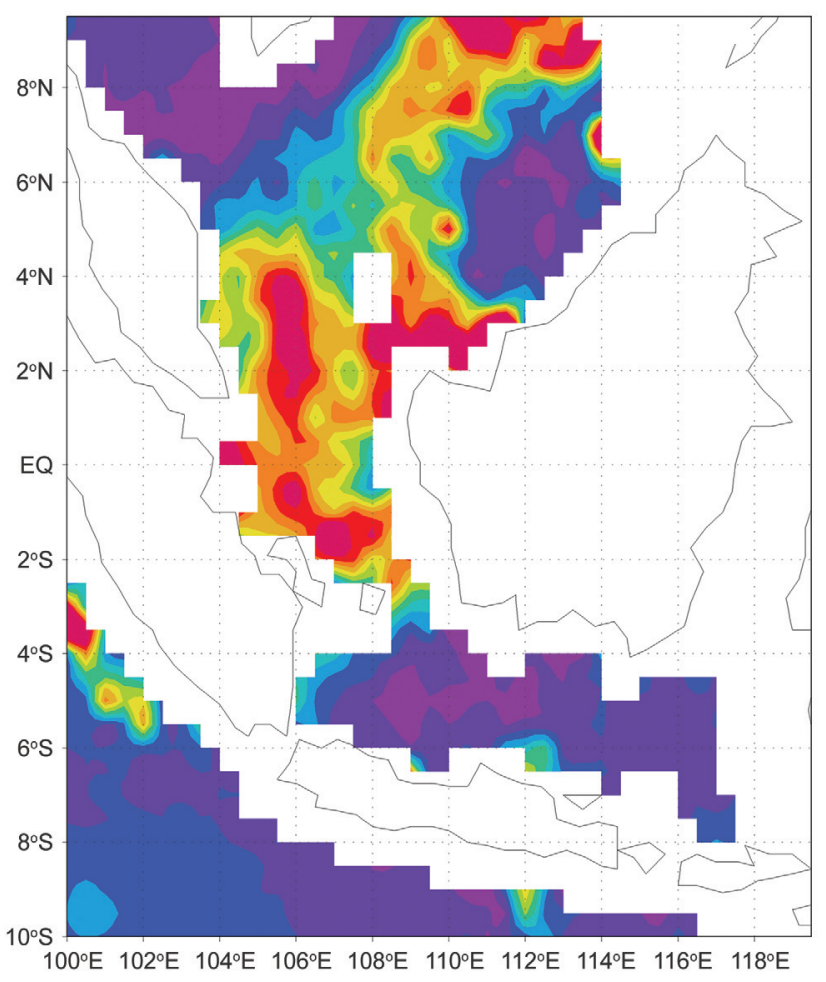

$\begin{array}{lllllllllll}0 & 40 & 80 & 120 & 160 & 200 & 240 & 280 & 320 & 360 & 400\end{array}$

Fig. 7. The SSM/I derived mean total air-sea heat flux distribution (sensible and latent) on 25 December 2001.
6 - 9 December 1999 (the third suitable period) and 21 26 December 1999 (the fourth suitable period), there were both a strong surge index and energy source (Figs. 4 and 6f $\sim$ h). However the location of the Borneo vortex at 1000 UTC 22 December 1999 was closer to land (Fig. 9a) than the period before Vamei formed (Fig. 2). Also the former did not stay on the ocean for several days (Figs. 9a d). Therefore, the northeasterly cold surge did not help spur the formation of a strong vortex. Moreover, as seen in Fig. 10 and Table 1, the LHF values for 21 - 26 December 1999 and 21 - 26 December 2001 were $12.72 \times 10^{14} \mathrm{~W}$ and $16.25 \times$ $10^{14} \mathrm{~W}$, respectively. Cloud clusters were observed in both areas during the two periods. Comparison in the LHR values showed that the value $\left(55.25 \times 10^{14} \mathrm{~W}\right)$ in 2001 was two times larger than that $\left(29.04 \times 10^{14} \mathrm{~W}\right)$ in 1999 , which revealed the former's significance in 2001. The larger LHR released from the rainfall activity ensured a larger total thermal energy influx (SHF + LHF + LHR) which may help the growth of stronger convections and provide a positive feedback for the newly developed typhoon. It is worth noting that abundant moisture transferred from the ocean is very important for typhoon convection development. Once a typhoon makes landfall, the moisture source is definitely cut

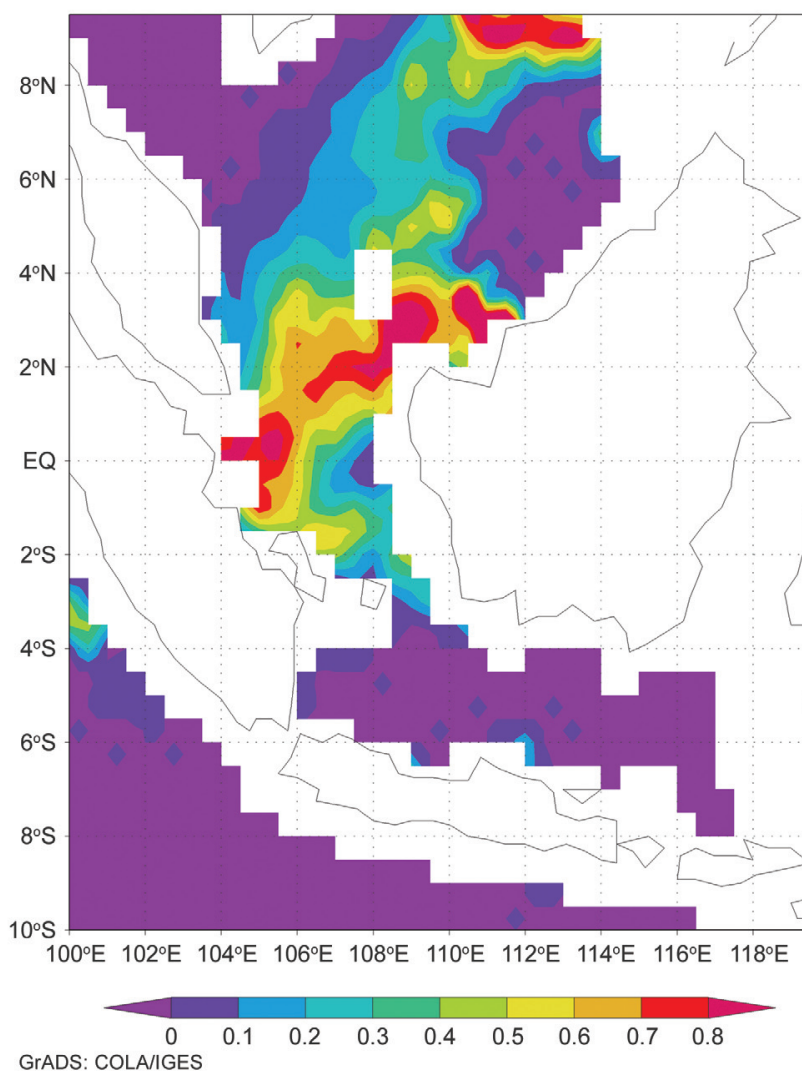

Fig. 8. The SSM/I derived mean rainfall rate distributions on 25 December 2001. 
(a)

1000 UTC 22 December 1999 QSCAT WS (kts)

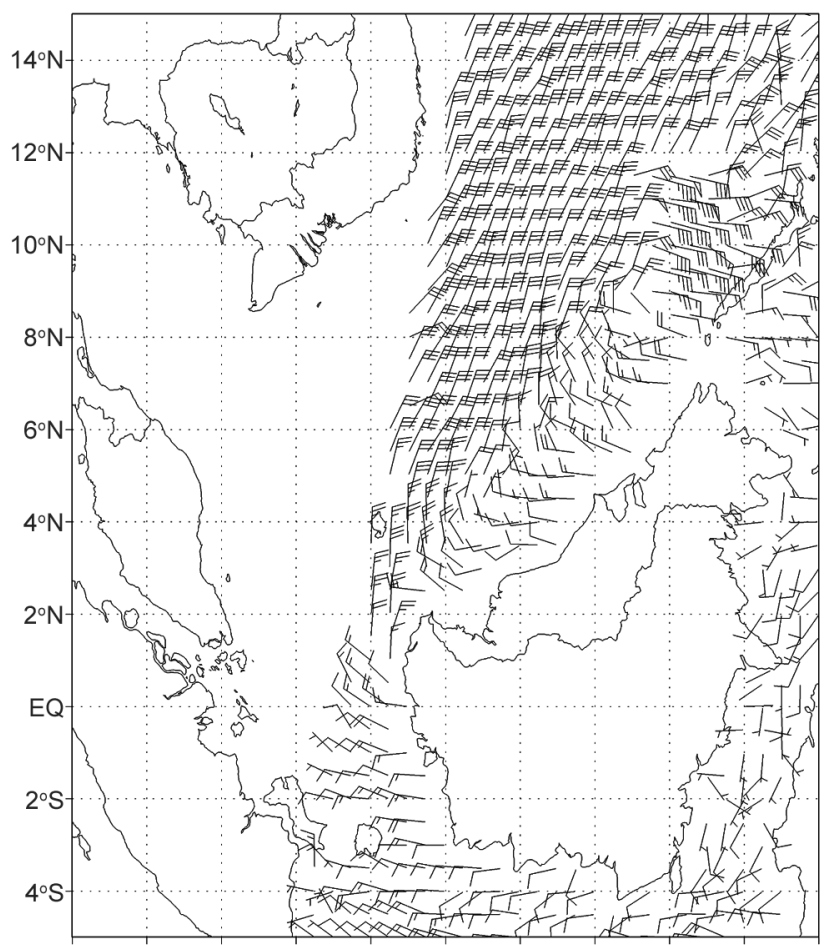

$100^{\circ} \mathrm{E} 102^{\circ} \mathrm{E} 104^{\circ} \mathrm{E} 106^{\circ} \mathrm{E} 108^{\circ} \mathrm{E} 110^{\circ} \mathrm{E} 112^{\circ} \mathrm{E} 114^{\circ} \mathrm{E}$ 116 $6^{\circ} \mathrm{E} 118^{\circ} \mathrm{E} 120^{\circ} \mathrm{E}$

(c)

2200 UTC 24 December 1999 QSCAT WS (kts)

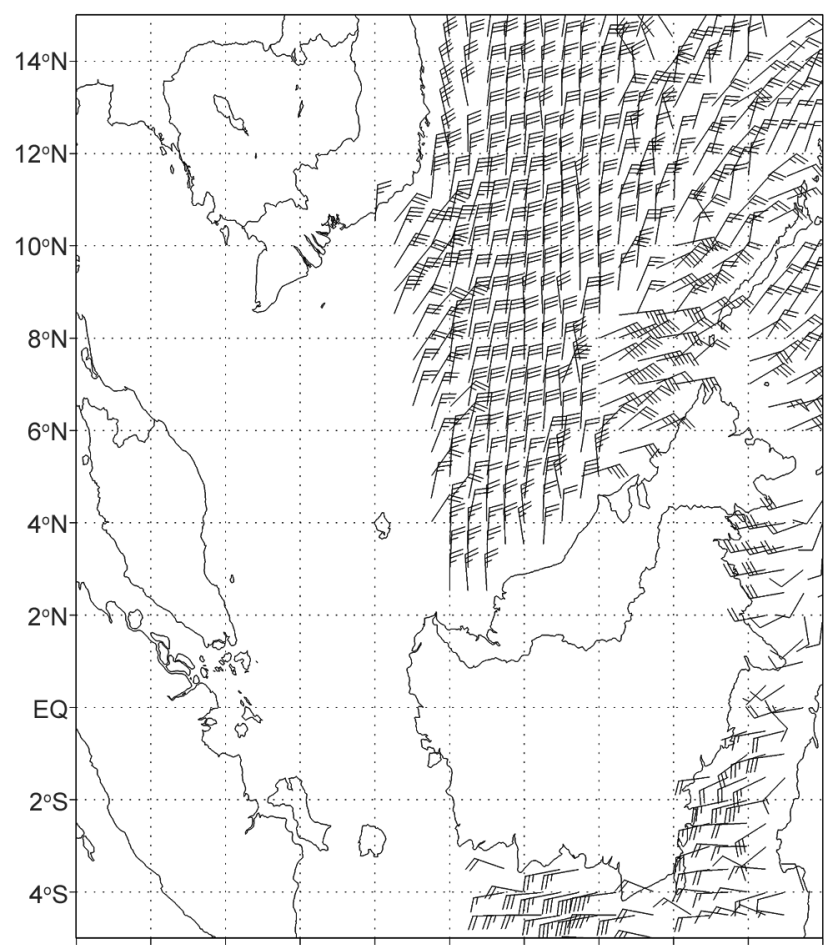

(b) 2200 UTC 23 December 1999 QSCAT WS (kts)

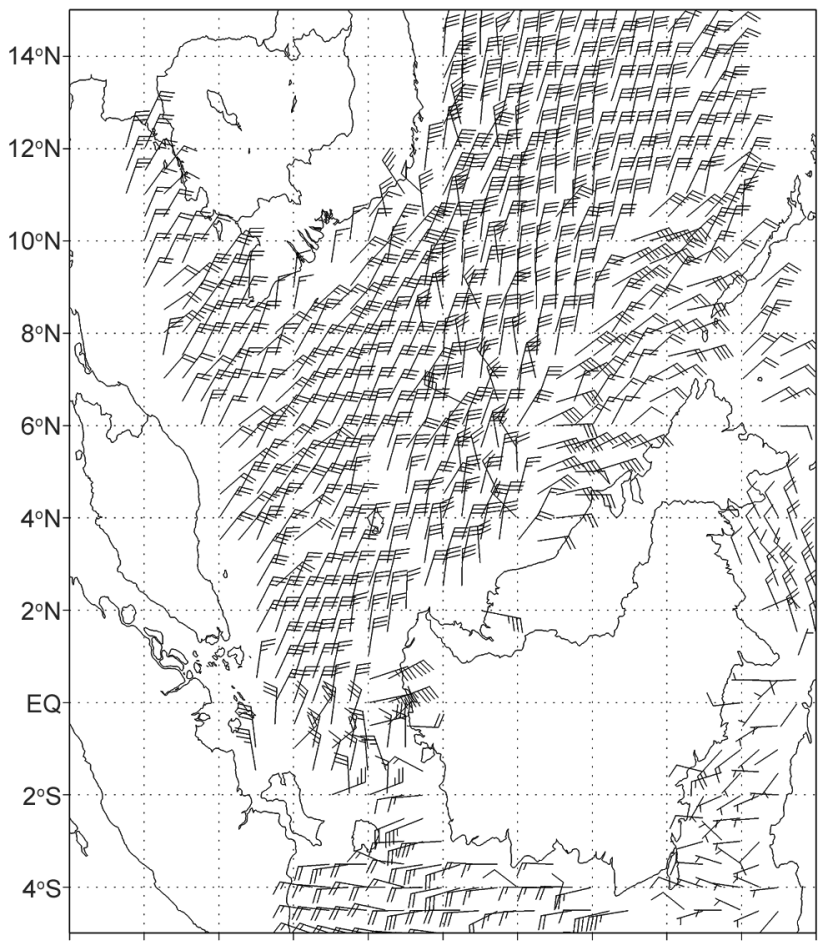

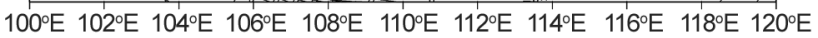

(d)

1000 UTC 25 December 1999 QSCAT WS (kts)

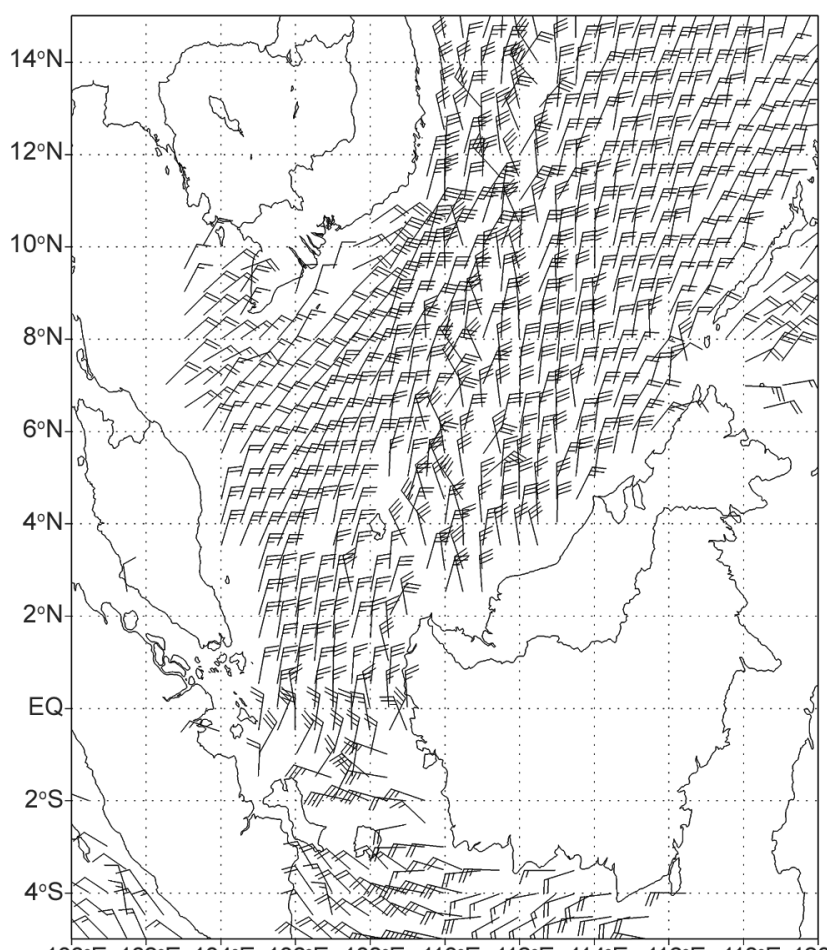

$100^{\circ} \mathrm{E} 102^{\circ} \mathrm{E} 104^{\circ} \mathrm{E} 106^{\circ} \mathrm{E} 108^{\circ} \mathrm{E} 110^{\circ} \mathrm{E} 112^{\circ} \mathrm{E} 114^{\circ} \mathrm{E} 116^{\circ} \mathrm{E} 118^{\circ} \mathrm{E} 120^{\circ} \mathrm{E}$

Fig. 9. A sequence of QSCAT wind analysis during 22 - 25 December 1999. 


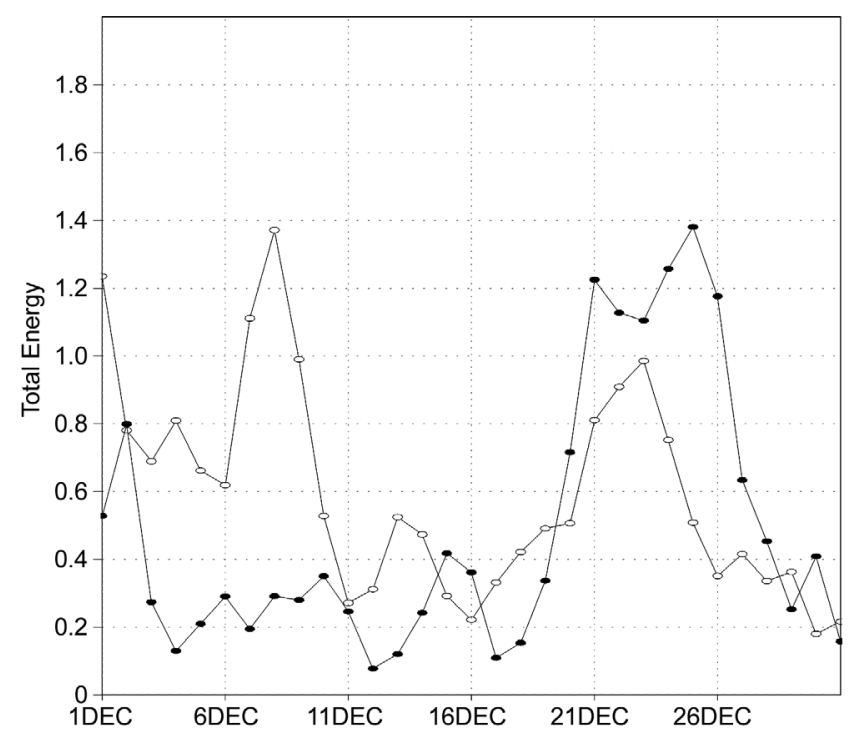

Fig. 10. Comparison of the total thermal energy (SHF + LHF + LHR; Unit: $10^{15} \mathrm{~W}$ ) covering the area from $5^{\circ} \mathrm{S}$ to $5^{\circ} \mathrm{N}$ and 102.5 to $112.5^{\circ} \mathrm{E}$ during December 1999 (hollow circles) and 2001 (solid dots).

Table 1. Mean values of SHF, LHF and LHR fluxes over the areas from $5^{\circ} \mathrm{S}$ to $5^{\circ} \mathrm{N}$ and 102.5 to $112.5^{\circ} \mathrm{E}$ during three different time periods.

\begin{tabular}{|c|c|c|}
\hline & $\begin{array}{c}1999 \\
(12 / 21-12 / 26)\end{array}$ & $\begin{array}{c}2001 \\
(12 / 21-12 / 26)\end{array}$ \\
\hline $\operatorname{SHF}(\mathrm{W}) \times 10^{14}$ & 0.92 & 1.21 \\
\hline $\operatorname{LHF}(\mathrm{W}) \times 10^{14}$ & 12.72 & 16.25 \\
\hline $\operatorname{LHR}(\mathrm{W}) \times 10^{14}$ & 29.04 & 55.25 \\
\hline Total $(\mathrm{W}) \times 10^{14}$ & 42.66 & 72.71 \\
\hline
\end{tabular}

off and combined with the larger surface friction will consequently make typhoon convection decays. It is the reason why high LHR can also occur over land but no typhoons develop over land.

\section{CONCLUSION}

The formation of Typhoon Vamei was an extremely rare occurrence. In addition to the weakening Coriolis force near the equatorial belt, the small ocean hinder in the South China Sea served as a strong barrier to a typhoon's formation. Previous studies mainly paid attention to its dynamic environment. Therefore, an energy analysis provides additional clues in understanding how such unusual equatorial systems interact with total thermal energy influx (SHF + LHF + LHR) and the air-sea energy environment. As stated by previous studies, the results of our research also illus- trate that a typhoon's intensity is highly correlated to the sea surface temperature, as well as the temperature of the upper layer ocean (Emanuel 2005).

In this paper, the mechanisms behind the growth and subsequent dissipation of Typhoon Vamei were examined by relevant satellite data retrievals. Through satellite-derived air-sea fluxes and rainfall rates, it shows that conducive energy conditions in 2001 may assist in the formation and growth of Vamei in 2001, which stemmed from the stronger LHR released by the rainfall activity during the pre-formation period. The energy effect on Vamei was significant, especially when compared with the air-sea conditions in 1999.

However, it is also important to keep in mind that there are many other factors in the formation and growth of a typhoon, such as vertical wind shear, upper level divergence, etc. More simulations and low-latitude typhoon case analysis are recommended for the investigations of such rare typhoons. In addition, continued research should be conducted to further understand how global warming impacts the LHR variations.

Acknowledgements We would like to express our gratitude to the National Science Council in supporting the NSC962745-M-008-002 Grant, and NSC97-2111-M-008-005 Grant. We would also like to thank the NOAA SAA system for providing the SSM/I data.

\section{REFERENCES}

Anthes, R. A., 1982: Tropical Cyclones, Their Evolution, Structure and Effects. American Meteorological Society, Boston, 208 pp.

Chambers, C. R. S. and T. Li, 2007: Simulation of formation of a near-equatorial typhoon Vamei (2001). Meteorol. Atmos. Phys., 98, 67-80, doi: 10.1007/s00703-00 6-0229-0. [Link]

Chang, C. P. and J. M. Chen, 1992: A statistical study of winter monsoon cold surges over the South China Sea and the large-scale equatorial divergence. J. Meteorol. Soc. Jpn., 70, 287-302.

Chang, C. P., J. E. Millard, and G. T. J. Chen, 1983: Gravitational character of cold surges during Winter MONEX. Mon. Weather Rev., 111, 293-307, doi: 10.1175/15200493(1983)111<0293:GCOCSD>2.0.CO;2. [Link]

Chang, C. P., C. H. Liu, and H. C. Kuo, 2003: Typhoon Vamei: An equatorial tropical cyclone formation. Geophys. Res. Lett., 30, 1150, doi: 10.1029/2002GL0163 65. [Link]

Chang, C. P., P. A. Harr, and H. J. Chen, 2005: Synoptic Disturbances over the Equatorial South China Sea and Western Maritime Continent during Boreal Winter. Mon. Weather Rev., 133, 489-503, doi: 10.1175/MWR -2868.1. [Link] 
Elsner, J. B., A. A. Tsonis, and T. H. Jagger, 2006: Highfrequency variability in hurricane power dissipation and its relationship to global temperature. Bull. Amer. Meteorol. Soc., 87, 763-768, doi: 10.1175/BAMS-87-6 -763. [Link]

Emanuel, K. A., 1986: An air-sea interaction theory for tropical cyclones. Part I: Steady-state maintenance. $J$. Atmos. Sci., 43, 585-605, doi: 10.1175/1520-0469(19 86)043<0585:AASITF>2.0.CO;2. [Link]

Emanuel, K. A., 1995: Sensitivity of tropical cyclones to surface exchange coefficients and a revised steadystate model incorporating eye dynamics. J. Atmos. Sci., 52, 3969-3976, doi: 10.1175/1520-0469(1995)052<39 69:SOTCTS>2.0.CO;2. [Link]

Emanuel, K. A., 2005: Increasing destructiveness of tropical cyclones over the past 30 years. Nature, 436, 686688, doi: 10.1038/nature03906. [Link]

Emanuel, K. A., 2007: Comment on "Sea-surface temperatures and tropical cyclones in the Atlantic basin" by Patrick J. Michaels, Paul C. Knappenberger, and Robert E. Davis. Geophys. Res. Lett., 34, L06702, doi: 10.1029/2006GL026942. [Link]

Ferraro, R. R., 1997: SSM/I derived global rainfall estimates for climatological applications. J. Geophys. Res., 102, 16715-16735.

Ferraro, R. R. and G. F. Marks, 1995: The development of SSM/I rain-rate retrieval algorithms using groundbased radar measurements. J. Atmos. Ocean. Technol., 12, 755-770, doi: 10.1175/1520-0426(1995)012<0755 :TDOSRR > 2.0.CO;2. [Link]

Goni, G. J. and J. A. Trinanes, 2003: Ocean thermal structure monitoring could aid in the intensity forecast of tropical cyclones. Eos, Trans., AGU, 84, 573-580, doi: 10.1029/2003EO510001. [Link]

Goodberlet, M. A. and C. T. Swift, 1992: Improved retrievals form the DMSP wind speed algorithm under adverse weather condition. IEEE Trans. Geosci. Remote Sensing, 30, 1076-1077.

Gray, W. M., 1968: Global view of the origin of the tropical disturbances and storm. Mon. Weather Rev., 96, 669700, doi: 10.1175/1520-0493(1968)096<0669:GVOT OO $>2.0 . \mathrm{CO} ; 2$. [Link]

Hendricks, E. A., M. T. Montgomery, and C. A. Davis, 2004: The role of "vortical" hot towers in the formation of Tropical Cyclone Diana (1984). J. Atmos. Sci., 61, 1209-1232, doi: 10.1175/1520-0469(2004)061<12 09:TROVHT>2.0.CO;2. [Link]

Hogan, T. F. and L. R. Brody, 1993: Sensitivity studies of the Navy's global forecast model parameterizations and evaluation of improvements to NOGAPS. Mon. Weather Rev., 121, 2373-2395, doi: 10.1175/1520-049 3(1993) $121<2373:$ SSOTNG $>2.0 . C O ; 2$. [Link]

Hollinger, J. P., J. L. Peirce, and G. A. Poe, 1990: SSM/I instrument evaluation. IEEE Trans. Geosci. Remote
Sensing, 28, 781-790.

Johnson, R. H. and R. A. Houze, Jr., 1987: Precipitating clouds systems of the Asian monsoon. In: Chang, C. P. and T. N. Krishnamurti (Eds.), Monsoon Meteorology, Oxford University Press, 298-353.

Juneng, L., F. T. Tangang, C. J. C. Reason, S. Moten, and W. A. W. Hassan, 2007: Simulation of tropical cyclone Vamei (2001) using the PSU/NCAR MM5 model. $M e$ teorol. Atmos. Phys., 97, 273-290, doi: 10.1007/s00703 -007-0259-2. [Link]

Kalnay, E., M. Kanamitsu, R. Kistler, W. Collins, D. Deaven, L. Gandin, M. Iredell, S. Saha, G. White, J. Woollen, Y. Zhu, A. Leetmaa, R. Reynolds, M. Chelliah, W. Ebisuzaki, W. Higgins, J. Janowiak, K. C. Mo, C. Ropelewski, J. Wang, R. Jenne, and D. Joseph, 1996: The NCEP/NCAR 40-year reanalysis project. Bull. Amer. Meteorol. Soc., 77, 437-471, doi: 10.1175/15200477(1996)077<0437:TNYRP>2.0.CO;2. [Link]

Konda, M., N. Imasato, and A. Shibata, 1996: A new method to determine near-sea surface air temperature by using satellite data. J. Geophys. Res., 101, 1434914360.

Liu, C. C., G. R. Liu, W. J. Chen, and H. Y. Yang, 2003: Modified Bowen ratio method in near-sea surface air temperature estimation by using satellite data, IEEE Trans. Geosci. Remote Sensing, 41, 1025-1033, doi: 10.1109/TGRS.2003.811079. [Link]

Liu, G. R., C. C. Liu, and T. H. Kuo, 2001: A contrast and comparison of near-sea surface air temperature/humidity form GMS and SSM/I Data with an Improved Algorithm. IEEE Trans. Geosci. Remote Sensing, 39, 2148-2157.

Liu, G. R., C. C. Liu, and T. H. Kuo, 2002: A Satellite-derived objective potential index for MCS development during the Mei-Yu period. J. Meteorol. Soc. Jpn., 80, 503-517.

McBride, J. L., 1995: Tropical cyclone formation. In: Elsberry, R. L. (Ed.), Global Perspective on Tropical Cyclones, WMO/TD-No. 693, World Meteorological Organization, 63-105.

Montgomery, M. T., M. E. Nicholls, T. A. Cram, and A. B. Saunders, 2006: A vortical hot tower route to tropical cyclogenesis. J. Atmos. Sci., 63, 355-386, doi: 10.1175/ JAS3604.1. [Link]

Reasor, P. D., M. T. Montgomery, and L. F. Bosart, 2005: Mesoscale observations of the genesis of Hurricane Dolly (1996). J. Atmos. Sci., 62, 3151-3171, doi: 10.11 75/JAS3540.1. [Link]

Rodgers, E. B. and H. F. Pierce, 1995: A satellite observational study of precipitation characteristics in Western North Pacific tropical cyclones. J. Appl. Meteorol., 34, 2587-2599, doi: 10.1175/1520-0450(1995)034<2587: ASOSOP $>2.0 . \mathrm{CO} ; 2$. [Link]

Schade, L. R., 2000: Tropical cyclone intensity and sea sur- 
face temperature. J. Atmos. Sci., 57, 3122-3130.

Shay, L. K., G. J. Goni, and P. G. Black, 2000: Effects of a warm oceanic feature on Hurricane Opal. Mon. Weather Rev., 128, 1366-1383, doi: 10.1175/1520-0493(200 0) $128<1366$ :EOAWOF>2.0.CO;2. [Link]

Sippel, J. A., J. W. Nielsen-Gammon, and S. E. Allen, 2006. The multiple-vortex nature of tropical cyclogenesis.
Mon. Weather Rev., 134, 1796-1814, doi: 10.1175/MW R3165.1. [Link]

Tory, K. J., N. E. Davidson, and M. T. Montgomery, 2007: Prediction and diagnosis of tropical cyclone formation in an NWP system. Part III: Developing and nondeveloping storms. J. Atmos. Sci., 64, 3195-3213, doi: 10.1175/JAS4023.1. [Link] 